\title{
Electronic properties of $\mathrm{Zr}_{4} M_{2} \mathrm{O}(M=\mathrm{Fe}, \mathrm{Co}, \mathrm{Ni})$ intermetallic compounds: first-principles APW+LO calculations and X-ray photoelectron spectroscopy data
}

\author{
A.A. LAVRENTYEV ${ }^{1}$, B.V. GABRELIAN ${ }^{1}$, P.N. SHKUMAT ${ }^{1}$, E.I. KOPYLOVA ${ }^{2}$, I.Y. NIKIFOROV ${ }^{1}$, \\ I.Y. ZAVALIY ${ }^{3}$, A.K. SINELNICHENKO ${ }^{2}$, O.Y. KHYZHUN ${ }^{2} *$ \\ ${ }^{1}$ Faculty of Physics, Don State Technical University, Gagarin Sq. 1, 344010 Rostov-on-Don, \\ Russian Federation \\ ${ }^{2}$ Frantsevych Institute for Problems of Materials Science, National Academy of Sciences of Ukraine, \\ Krzhyzhanovskoho St. 3, 03142 Kyiv, Ukraine \\ ${ }^{3}$ Karpenko Physico-Mechanical Institute, National Academy of Sciences of Ukraine, \\ Naukova St. 5, 79601 Lviv, Ukraine \\ * Corresponding author. Tel.: +380-44-4243364, fax: +380-44-4242131; e-mail: khyzhun@ipms.kiev.ua
}

Received September 22, 2013; accepted December 25, 2013; available on-line August 30, 2014

First-principles band-structure augmented plane wave + local orbitals (APW+LO) calculations as incorporated in the WIEN2k code, as well as X-ray photoelectron spectroscopy (XPS) measurements, were performed to elucidate the electronic structure of the $\mathrm{Zr}_{4} M_{2} \mathrm{O}(M=\mathrm{Fe}$, Co, Ni) oxides, very prospective hydrogen-storage materials. Total and partial densities of states for the oxides were derived from the APW+LO calculations. Our calculations show that the $O 2 p$ states make the major contributions at the bottom of the valence band, while the $M 3 d$ and $\mathrm{Zr} 4 d$ states are the dominant contributors at the top of the valence band and at the bottom of the conduction band. Peculiarities of the occupation of the valence band predicted by the $\mathrm{APW}+\mathrm{LO}$ calculations for $\mathrm{Zr}_{4} \mathrm{Fe}_{2} \mathrm{O}$ are confirmed experimentally by comparison on a common energy scale of the XPS valence-band spectrum and the curve of total DOS.

Alloys / Intermetallic compounds / First-principles calculations / X-ray photoelectron spectroscopy / Electronic structure

\section{Introduction}

Binary intermetallic compounds $\mathrm{Zr}_{2} M$ ( $M$ stands for transition metal) are recognized as effective hydrogen absorbing and hydrogen getter materials. Among these compounds, particularly remarkable are $\mathrm{Zr}_{2} M$ ( $M=\mathrm{Fe}, \mathrm{Co}, \mathrm{Ni}$ ) compounds (crystallizing in the $\mathrm{CuAl}_{2}$-type structure), which attract much attention as hydrogen storage materials since they absorb significant amounts of hydrogen (more than one hydrogen atom per metal atom). A number of intermetallic $\mathrm{CuAl}_{2}$-type hydrides (deuterides) with $\mathrm{H}(\mathrm{D})$-to-metal ratios exceeding one have been reported, e.g. $\mathrm{Zr}_{2} \mathrm{FeH}_{\sim 4.5}, \mathrm{Zr}_{2} \mathrm{FeD}_{5}, \mathrm{Zr}_{2} \mathrm{CoD}_{4.85}$, and $\mathrm{Zr}_{2} \mathrm{NiD}_{4.74}$ [1-3].

However, $\mathrm{Zr}_{2} M(M=\mathrm{Fe}, \mathrm{Co}, \mathrm{Ni})$ compounds also attract significant attention from scientific and technological viewpoints because of their ability to incorporate oxygen leading to formation of ternary oxygen-stabilized $\mathrm{Zr}_{4} M_{2} \mathrm{O}$ phases [4-6]. The crystal structure of the oxygen-stabilized $\mathrm{Zr}_{4} M_{2} \mathrm{O}(M=\mathrm{Fe}$, $\mathrm{Co}, \mathrm{Ni}$ ) phases belongs to the $\eta-\mathrm{Fe}_{3} \mathrm{~W}_{3} \mathrm{C}$-type, which can be viewed as a filled derivative of the $\mathrm{Ti}_{2} \mathrm{Ni}$-type structure. Among the above mentioned oxygenstabilized $\eta$-phases, detailed hydrogen absorption/ desorption properties have been reported for the $\mathrm{Zr}_{4} \mathrm{Fe}_{2} \mathrm{O}_{x}$ compound [3,7]. It has been established that the hydrogen absorption/desorption properties of $\eta-\mathrm{Zr}_{4} \mathrm{Fe}_{2} \mathrm{O}_{x}$ are strongly affected by the oxygen content. The hydrogen storage capacity of $\mathrm{Zr}_{4} \mathrm{Fe}_{2} \mathrm{O}_{x}$ was found to decrease with increasing O-content, and the highest hydrogenation capacities are characteristic of the low-oxygen $\eta$-phases, namely $\mathrm{Zr}_{4} \mathrm{Fe}_{2} \mathrm{O}_{0.3} \mathrm{H}_{9.4}$ and $\mathrm{Zr}_{4} \mathrm{Fe}_{2} \mathrm{O}_{0.25} \mathrm{H}_{9.9}[7,8]$. These capacities exceed the highest hydrogenation capacity achieved for the saturated hydride $\mathrm{Zr}_{2} \mathrm{FeH}_{\sim 4.5}$ [3]. It is worth mentioning also that the oxygen-stabilized $\mathrm{Zr}_{4} \mathrm{Fe}_{2} \mathrm{O}_{x}$ phase was found to be more stable against hydrogen disproportionation than the $\mathrm{Zr}_{2} \mathrm{Fe}$ compound $[9,10]$. Detailed studies of the dependence of the cell parameter $a$ upon the oxygen content $x$ in $\mathrm{Zr}_{4} \mathrm{Fe}_{2} \mathrm{O}_{x}$ oxide have indicated that the $a$ value changes only slightly when the $x$ value is varied within the $0.25 \leq x \leq 0.6$ homogeneity region $[4,7,8]$. 
The aim of the present work is a complex study of the electronic structure of $\mathrm{Zr}_{4} M_{2} \mathrm{O}(M=\mathrm{Fe}, \mathrm{Co}, \mathrm{Ni})$ compounds. For this purpose, we have applied the augmented plane wave + local orbitals $(\mathrm{APW}+\mathrm{LO})$ method as incorporated in the WIEN2k code [11]. To verify our theoretical data, the X-ray photoelectron spectroscopy (XPS) method was used.

\section{Experimental}

$\mathrm{Zr}_{4} M_{2} \mathrm{O}_{x}(M=\mathrm{Fe}, \mathrm{Ni})$ compounds were synthesized by arc melting in a purified argon atmosphere on a water-cooled copper hearth from appropriate quantities of high-purity metal powders ( $\mathrm{Zr} 99.8 \%$, $\mathrm{Fe}(\mathrm{Ni}) 99.9 \%$ ) and chemically pure $\mathrm{ZrO}_{2}$, employing the technique described in detail in [7]. Our attempts to synthesize $\mathrm{Zr}_{4} \mathrm{Co}_{2} \mathrm{O}_{x}$ compounds were unsuccessful. The as-cast $\mathrm{Zr}_{4} M_{2} \mathrm{O}_{x}(M=\mathrm{Fe}, \mathrm{Ni})$ samples were annealed in vacuum at $1000^{\circ} \mathrm{C}$ for $300 \mathrm{~h}$ to achieve homogeneity. X-ray diffraction (XRD) phase analysis of the samples, carried out with a HZG-4a diffractometer $\left(\mathrm{Cu} K_{\alpha}\right.$ radiation) revealed that the compounds crystallize in the cubic $\eta-\mathrm{Fe}_{3} \mathrm{~W}_{3} \mathrm{C}$-type structure belonging to the space group $F d-3 m$. The lattice parameters determined from our XRD data are the following: $a=12.210$ (2) $\AA$ (for $\mathrm{Zr}_{4} \mathrm{Fe}_{2} \mathrm{O}_{x}$ ) and $a=12.197(4) \AA \quad$ (for $\left.\mathrm{Zr}_{4} \mathrm{Ni}_{2} \mathrm{O}_{x}\right) \quad(x=0.6$ for both intermetallic compounds studied). Fig. 1 presents the crystal structure of $\mathrm{Zr}_{4} \mathrm{Fe}_{2} \mathrm{O}$ (space group $F d-3 m$, $Z=16$ ), which is analogous to that of $\mathrm{Zr}_{4} \mathrm{Ni}_{2} \mathrm{O}$ and $\mathrm{Zr}_{4} \mathrm{Co}_{2} \mathrm{O}$. The zirconium atoms in the structure of the $\mathrm{Zr}_{4} M_{2} \mathrm{O}(M=\mathrm{Fe}, \mathrm{Ni}, \mathrm{Co})$ compounds occupy two nonequivalent positions, namely $48 f$ and $16 d$ sites (labeled as $\mathrm{Zr} 1$ and $\mathrm{Zr} 2$, respectively), while the $\mathrm{Fe}$ ( $\mathrm{Ni}, \mathrm{Co}$ ) atoms are distributed on a $32 e$ site and the $\mathrm{O}$ atoms on the $16 c$ site.

The X-ray spectroscopy measurements of the $\mathrm{Zr}_{4} \mathrm{Ni}_{2} \mathrm{O}_{x}$ compound were carried out in a sublimation ion-pumped chamber, having a base pressure of less than $1 \times 10^{-7} \mathrm{~Pa}$, of an ES-2401 spectrometer. The energy scale of the spectrometer was calibrated by setting the measured $\mathrm{Au} 4 f_{7 / 2}$ and $\mathrm{Cu} 2 p_{3 / 2}$ binding energies (BEs) to $84.00 \pm 0.05 \mathrm{eV}$ and $932.66 \pm 0.05 \mathrm{eV}$, respectively, with regard to the Fermi energy, $E_{\mathrm{F}}$. The XPS spectra were excited by a $\operatorname{Mg} K_{\alpha}$ source of X-ray radiation $(E=1253.6 \mathrm{eV})$ and were recorded at a constant energy of $50 \mathrm{eV}$.

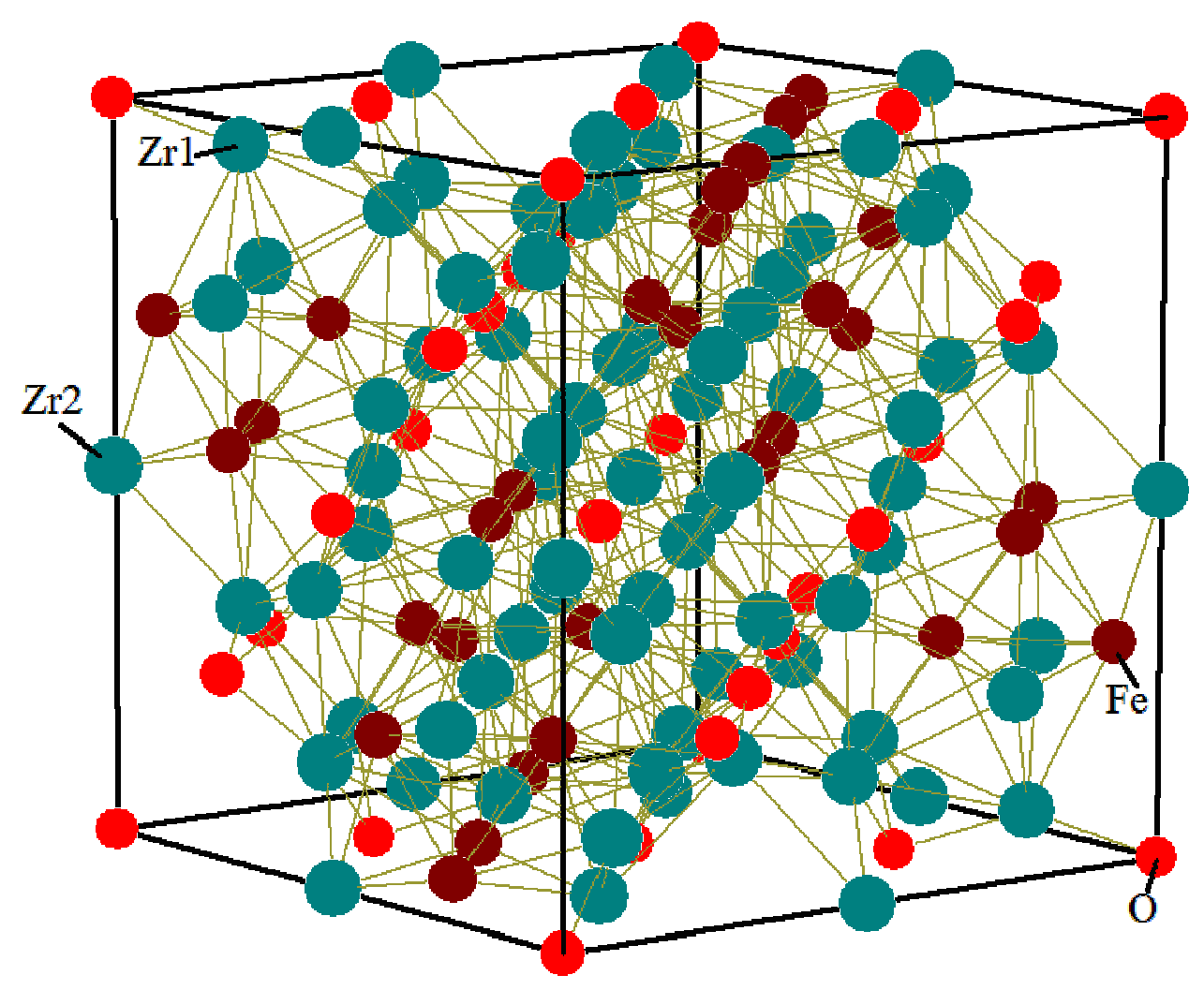

Fig. 1 Crystal structure of $\mathrm{Zr}_{4} \mathrm{Fe}_{2} \mathrm{O}$ : $\mathrm{O}$ - small circles, $\mathrm{Fe}$ - medium circles, $\mathrm{Zr}$ - large circles. 
To remove surface contaminations, bombardment of the sample surface was performed by $\mathrm{Ar}^{+}$ions with an energy of $2.0 \mathrm{keV}$ for $5 \mathrm{~min}$ at an ion current density of $15 \mu \mathrm{A} / \mathrm{cm}^{2}$. The method of surface cleaning was similar to that used earlier [12]. Data of the XPS characterization of the $\mathrm{Zr}_{4} \mathrm{Ni}_{2} \mathrm{O}_{x}$ sample, both for pristine and $\mathrm{Ar}^{+}$-bombarded surfaces, are shown in Fig. 2. The survey XPS spectrum of the pristine surface of $\mathrm{Zr}_{4} \mathrm{Ni}_{2} \mathrm{O}_{x}$ indicates that the pristine surface of the sample under study contains significant amounts of hydro-carbon adsorbents. Their presence does not allow detection of signals coming from nickel atoms when measuring the XPS spectra. However, after $\mathrm{Ar}^{+}$-bombardment of the $\mathrm{Zr}_{4} \mathrm{Ni}_{2} \mathrm{O}_{x}$ surface, all the spectral features, except the low-intensity $\mathrm{C} 1 \mathrm{~s}$ level, are assigned to be the constituent element core-levels or Auger lines. For the $\mathrm{Ar}^{+}$-bombarded surface with a very small C $1 s$ signal, the BE scale drift due to possible surface charging was accounted for using the $\mathrm{F} 1 \mathrm{~s}$ level $(685.0 \mathrm{eV})$ of fluorine adsorbed on the surface. Fluorine was specially introduced into the vacuum chamber for this purpose up to the appearance of a measurable $\mathrm{F} 1 \mathrm{~s}$ level. XPS characterization of the $\mathrm{Zr}_{4} \mathrm{Fe}_{2} \mathrm{O}_{x}$ compound has been done previously [13].

\section{Method of calculation}

Our $a b$ initio band-structure calculations of $\mathrm{Zr}_{4} \mathrm{Fe}_{2} \mathrm{O}$ were performed on the basis of the density functional theory (DFT). They were done using the APW+LO method with the WIEN2k code [14]. In the present APW $+\mathrm{LO}$ calculations, the positions of the atoms were those previously reported in [13], where calculations were performed for a hypothetically stoichiometric $\mathrm{Zr}_{4} \mathrm{Fe}_{2} \mathrm{O}$ compound with the lattice parameter $a=12.222 \AA$. In the present work the APW $+\mathrm{LO}$ calculations were performed with the lattice parameter $a=12.210 \AA$ derived from our experimental XRD study of the $\mathrm{Zr}_{4} \mathrm{Fe}_{2} \mathrm{O}_{0.6}$ compound with the maximum oxygen content. As in [13], the generalized gradient approximation (GGA) by Perdew et al. [15] was employed for the calculations of the exchange-correlation potential and the tetrahedron method by Blöchl et al. [16] was adopted for integration through the Brillouin zone. The basis function involves the atomic orbitals of $\mathrm{Zr}, \mathrm{Fe}$ and $\mathrm{O}$, as reported in [13]. The muffin-tin (MT) sphere radii of the constituent atoms in $\mathrm{Zr}_{4} \mathrm{Fe}_{2} \mathrm{O}$ were assumed to be $1.212,1.323$ and $1.074 \AA$ for $\mathrm{Zr}, \mathrm{Fe}$ and $\mathrm{O}$, respectively. The Brillouin zone sampling was done using $500 k$-points within the irreducible wedge of the zone. The $R_{\min }^{M T} k_{\max }$ parameter, where $R_{\min }^{M T}$ denotes the smallest MT sphere radius and $k_{\max }$ determines the value of the largest $k$ vector in the plane wave expansion, equals 7.0 (the charge density was Fourier expanded up to the value $G_{\max }=12 \mathrm{Ry}^{1 / 2}$ ). The iteration process was checked taking into account changes of the integral charge difference $q=\int\left|\rho_{n}-\rho_{n-1}\right| d r$, where $\rho_{n-1}(r)$ and $\rho_{n}(r)$ are input and output charge density, respectively.

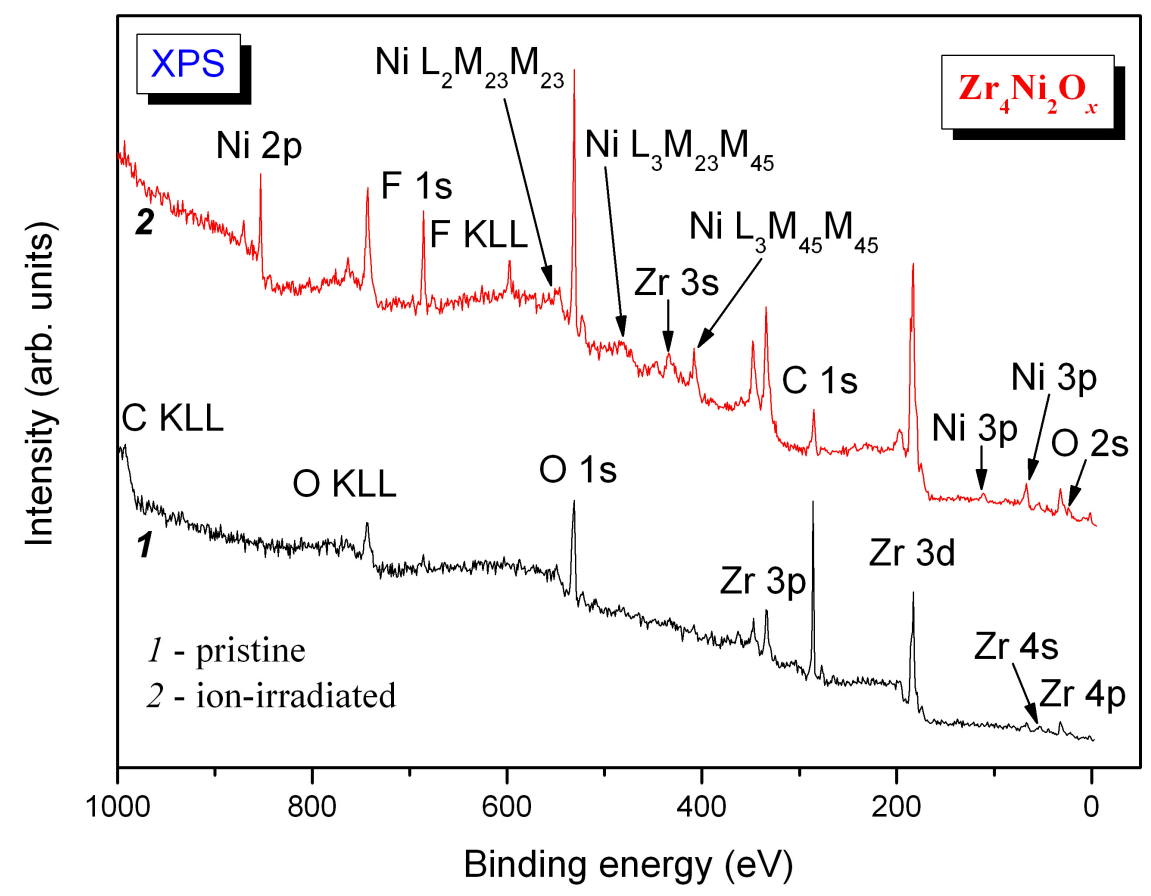

Fig. 2 Survey XPS spectra recorded for (1) pristine and (2) $\mathrm{Ar}^{+}$ion-bombarded surface of the $\mathrm{Zr}_{4} \mathrm{Ni}_{2} \mathrm{O}_{x}$ compound. 
The calculations were interrupted in the case of $q \leq 0.0001$. A similar technique was adopted for the calculations of the electronic structure of the $\mathrm{Zr}_{4} \mathrm{Co}_{2} \mathrm{O}$ and $\mathrm{Zr}_{4} \mathrm{Ni}_{2} \mathrm{O}$ compounds.

\section{Results and discussion}

Fig. 3 presents data from our calculations of the total DOS and partial densities of states of the atoms constituting $\mathrm{Zr}_{4} \mathrm{Fe}_{2} \mathrm{O}$. It is apparent that the upper core $\mathrm{Zr} 4 p$ and $\mathrm{O} 2 s$ states form rather broad bands in the $\mathrm{Zr}_{4} \mathrm{Fe}_{2} \mathrm{O}$ compound. The $\mathrm{Zr} 4 p$-like band consists of three sub-bands: the upper sub-band centered at $-26.2 \mathrm{eV}$ is formed mainly from contributions of the $4 p$ states associated with the $\mathrm{Zr} 2$ atoms, while the central and lower sub-bands centered at -27.15 and $-27.9 \mathrm{eV}$, respectively, mainly originate from contributions of the $4 p$ states of the $\mathrm{Zr} 1$ atoms, with smaller contributions of the $4 p$ states associated with the $\mathrm{Zr} 2$ atoms ( $c f$. Figs. 3 and 4). In addition, the band centered at $-20.35 \mathrm{eV}$ on the curve of the total DOS of $\mathrm{Zr}_{4} \mathrm{Fe}_{2} \mathrm{O}$ is mainly formed from contributions of the $\mathrm{O} 2 s$ states. Some minor contributions of the $4 p$ states of the $\mathrm{Zr} 1$ atoms into the O $2 s$-like sub-band on the curve of total DOS of $\mathrm{Zr}_{4} \mathrm{Fe}_{2} \mathrm{O}$ are also detected by our APW+LO calculations (see Figs. 3 and 4).

Fig. 3 shows that the valence band in the $\mathrm{Zr}_{4} \mathrm{Fe}_{2} \mathrm{O}$ compound, which ranges from -7.8 to $0 \mathrm{eV}$, can be divided into two energy regions, that are labelled $A$ $(0$ to $-4.15 \mathrm{eV})$ and $B(-5.95$ to $-7.8 \mathrm{eV})$. From Fig. 3,

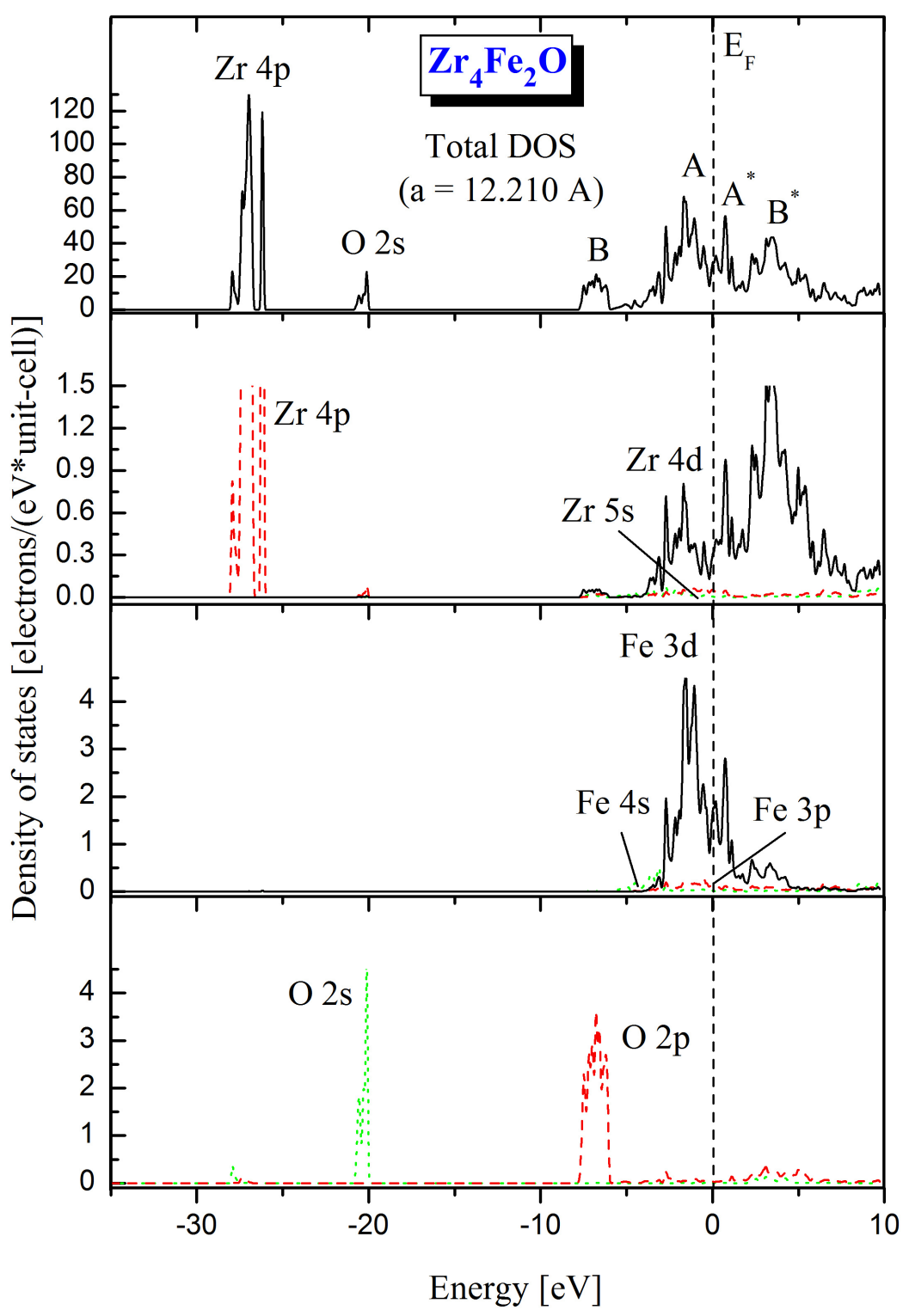

Fig. 3 Total DOS and partial densities of states of the atoms constituting the $\mathrm{Zr}_{4} \mathrm{Fe}_{2} \mathrm{O}$ compound. 


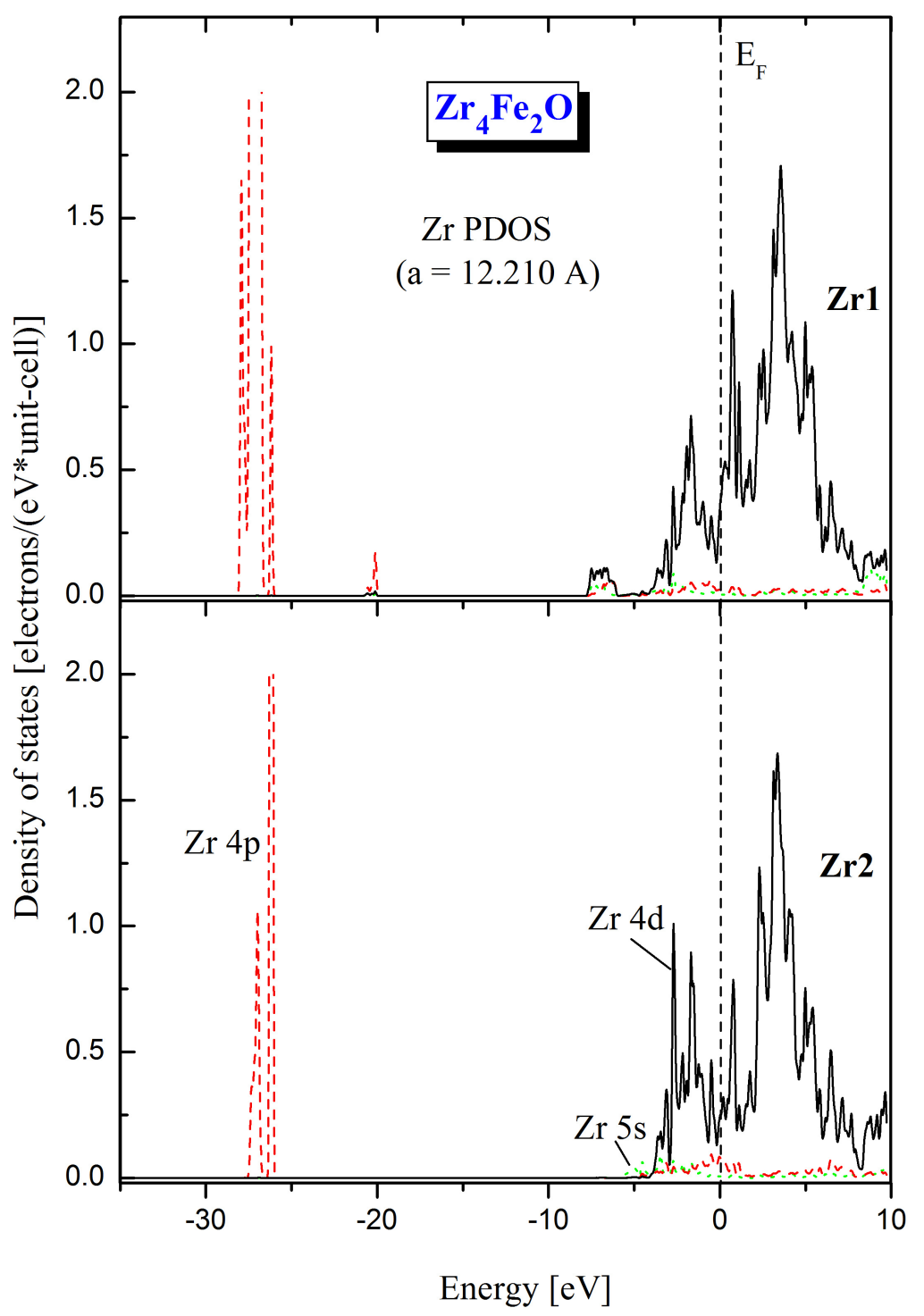

Fig. 4 Partial densities of states of the $\mathrm{Zr} 1$ and $\mathrm{Zr} 2$ atoms in the $\mathrm{Zr}_{4} \mathrm{Fe}_{2} \mathrm{O}$ compound.

one can see that the lower sub-band $B$ almost completely originates from contributions of the $\mathrm{O} 2 p$ states. However, smaller contributions of the $4 d$ states associated with the $\mathrm{Zr} 1$ atoms are also detected by our APW+LO data (see Fig. 4). This means that only the $\mathrm{Zr} 1$ atoms participate in the formation of the chemical bonding with oxygen in $\mathrm{Zr}_{4} \mathrm{Fe}_{2} \mathrm{O}$. The upper sub-band $A$ of the valence band of $\mathrm{Zr}_{4} \mathrm{Fe}_{2} \mathrm{O}$ is mainly formed from contributions of the $\mathrm{Fe} 3 d$ states with somewhat smaller contributions of the $\mathrm{Zr} 4 d$ states.

Two sub-bands, labelled $A^{*}$ and $B^{*}$, centered at about 0.7 and $3.5 \mathrm{eV}$, respectively, are prominent on the curve of total DOS of $\mathrm{Zr}_{4} \mathrm{Fe}_{2} \mathrm{O}$ near the bottom of the conduction band (Fig. 3). The bottom of the conduction band (the sub-band $A *$ ) mainly originates from contributions of the unoccupied Fe $3 d$ states, with smaller contributions of the unoccupied $\mathrm{Zr} 4 d$ states as well. Further, the sub-band $B^{*}$ of the conduction band of $\mathrm{Zr}_{4} \mathrm{Fe}_{2} \mathrm{O}$ is dominated by contributions of the unoccupied $\mathrm{Zr} 4 d$ states. Smaller contributions of unoccupied $\mathrm{Fe} 3 d$ states into the subband $B^{*}$ of the conduction band of $\mathrm{Zr}_{4} \mathrm{Fe}_{2} \mathrm{O}$ are also visible in our APW+LO calculations (Fig. 3).

Fig. 5 presents a comparison of the curve of total DOS of $\mathrm{Zr}_{4} \mathrm{Fe}_{2} \mathrm{O}$ with analogous curves for the other oxygen-stabilized $\eta$ - $\mathrm{Fe}_{3} \mathrm{~W}_{3} \mathrm{C}$-type compounds under study, namely $\mathrm{Zr}_{4} \mathrm{Co}_{2} \mathrm{O}$ and $\mathrm{Zr}_{4} \mathrm{Ni}_{2} \mathrm{O}$. It is apparent that the results of our theoretical $\mathrm{APW}+\mathrm{LO}$ studies indicate that, when going from $\mathrm{Zr}_{4} \mathrm{Fe}_{2} \mathrm{O}$ to $\mathrm{Zr}_{4} \mathrm{Co}_{2} \mathrm{O}$ and, further, to $\mathrm{Zr}_{4} \mathrm{Ni}_{2} \mathrm{O}$, the sub-bands $A^{*}$ and $B^{*}$ of the conduction band shift towards the Fermi level, whilst the sub-band $A$ of the valence band shifts away from $E_{\mathrm{F}}$. Nevertheless, the energy position of the subband $B$ of the valence band does not change. 


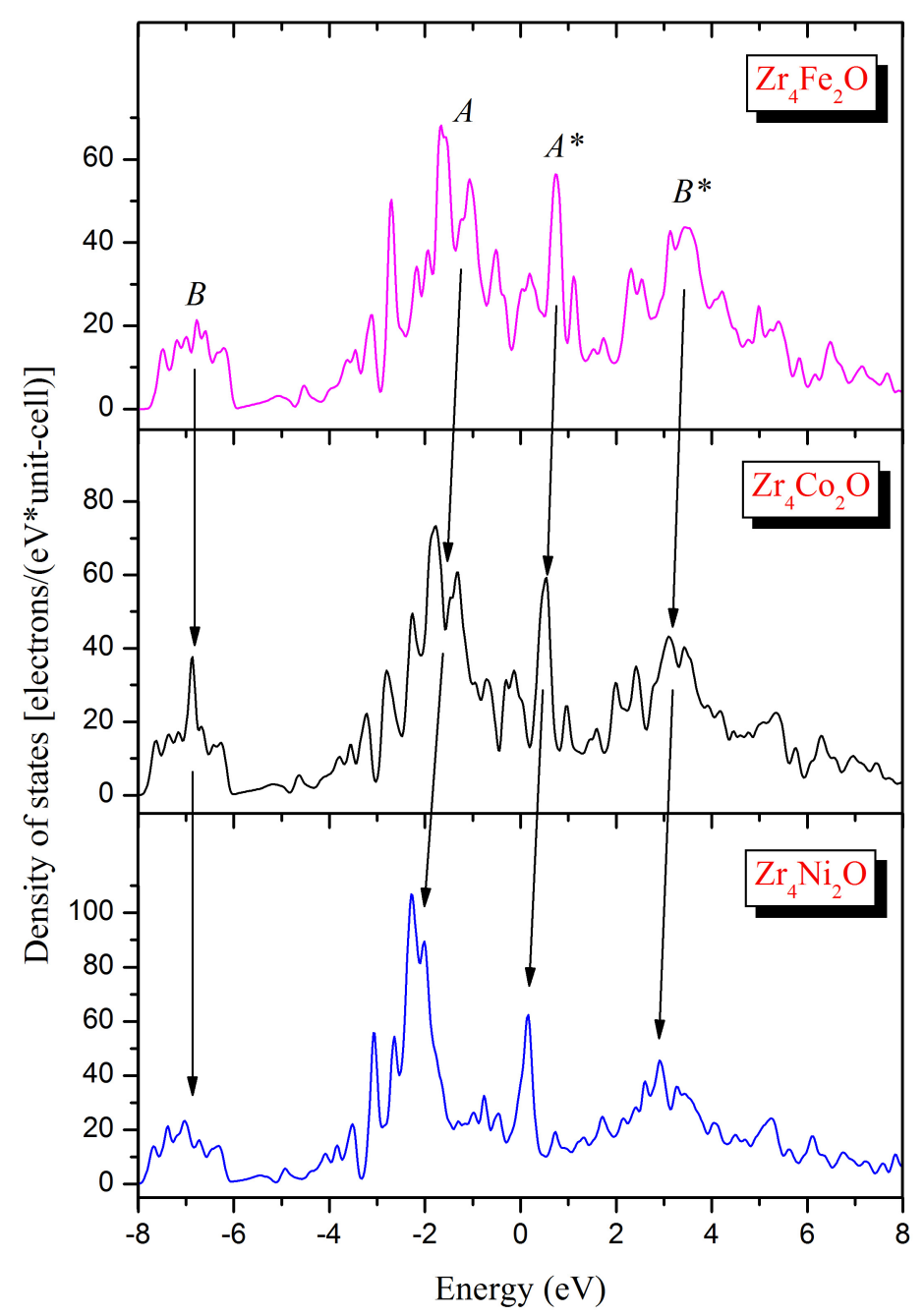

Fig. 5 Total DOS within the valence-band and conduction-band regions of the $\mathrm{Zr}_{4} M_{2} \mathrm{O}(M=\mathrm{Fe}, \mathrm{Ni}, \mathrm{Co})$ compounds.

Our theoretical calculations of the electronic structure of $\mathrm{Zr}_{4} \mathrm{Fe}_{2} \mathrm{O}$ seem to be in agreement with the experimental XPS results derived for $\mathrm{Zr}_{4} \mathrm{Fe}_{2} \mathrm{O}_{x}$ $(x=0.6)$ in [13]. Fig. 6 shows a comparison on a common energy scale of the curve of total DOS of $\mathrm{Zr}_{4} \mathrm{Fe}_{2} \mathrm{O}$ and its XPS valence-band spectrum. From Fig. 6, in accordance with our theoretical APW+LO data, the position of the maximum $B$ of the XPS valence-band spectrum of $\mathrm{Zr}_{4} \mathrm{Fe}_{2} \mathrm{O}_{x}$ corresponds well to the position of the low-energy sub-band $B$ of the curve of total DOS of $\mathrm{Zr}_{4} \mathrm{Fe}_{2} \mathrm{O}$, while the energy position of the sub-band $A$ of the theoretical curve is close to that of the near-Fermi feature $A$ of the XPS valence-band spectrum of $\mathrm{Zr}_{4} \mathrm{Fe}_{2} \mathrm{O}_{0.6}$.

Our APW+LO results indicate that the electronic structure of the $\mathrm{Zr}_{4} M_{2} \mathrm{O}$ compounds $(M=\mathrm{Fe}, \mathrm{Ni}, \mathrm{Co})$ is different from those of binary $\mathrm{Zr}, \mathrm{Fe}, \mathrm{Ni}$, and $\mathrm{Co}$ oxides [14,17-20], in which the O $2 p$ states mainly contribute in the upper portion of the valence band with additional significant contributions throughout the whole valence-band region. However, the electronic structure of the $\mathrm{Zr}_{4} M_{2} \mathrm{O}(M=\mathrm{Fe}, \mathrm{Ni}, \mathrm{Co})$ compounds resembles those of $\mathrm{Ti}_{4} \mathrm{Fe}_{2} \mathrm{O}$ and $\mathrm{Zr}_{3} \mathrm{~V}_{3} \mathrm{O}$, other representatives of the ternary oxygen-stabilized $\eta$-phases. Our first-principles calculations and XPS measurements of $\mathrm{Ti}_{4} \mathrm{Fe}_{2} \mathrm{O}$ and $\mathrm{Zr}_{3} \mathrm{~V}_{3} \mathrm{O}$ [21,22] indicated that the $\mathrm{O} 2 p$ states almost exclusively contribute at the bottom of the valence band.

\section{Conclusions}

Data of first-principles calculations using the APW + LO method as incorporated in the WIEN2k code revealed that the $\mathrm{O} 2 p$ states dominate at the bottom of the valence band of $\mathrm{Zr}_{4} \mathrm{Fe}_{2} \mathrm{O}$, while the top 


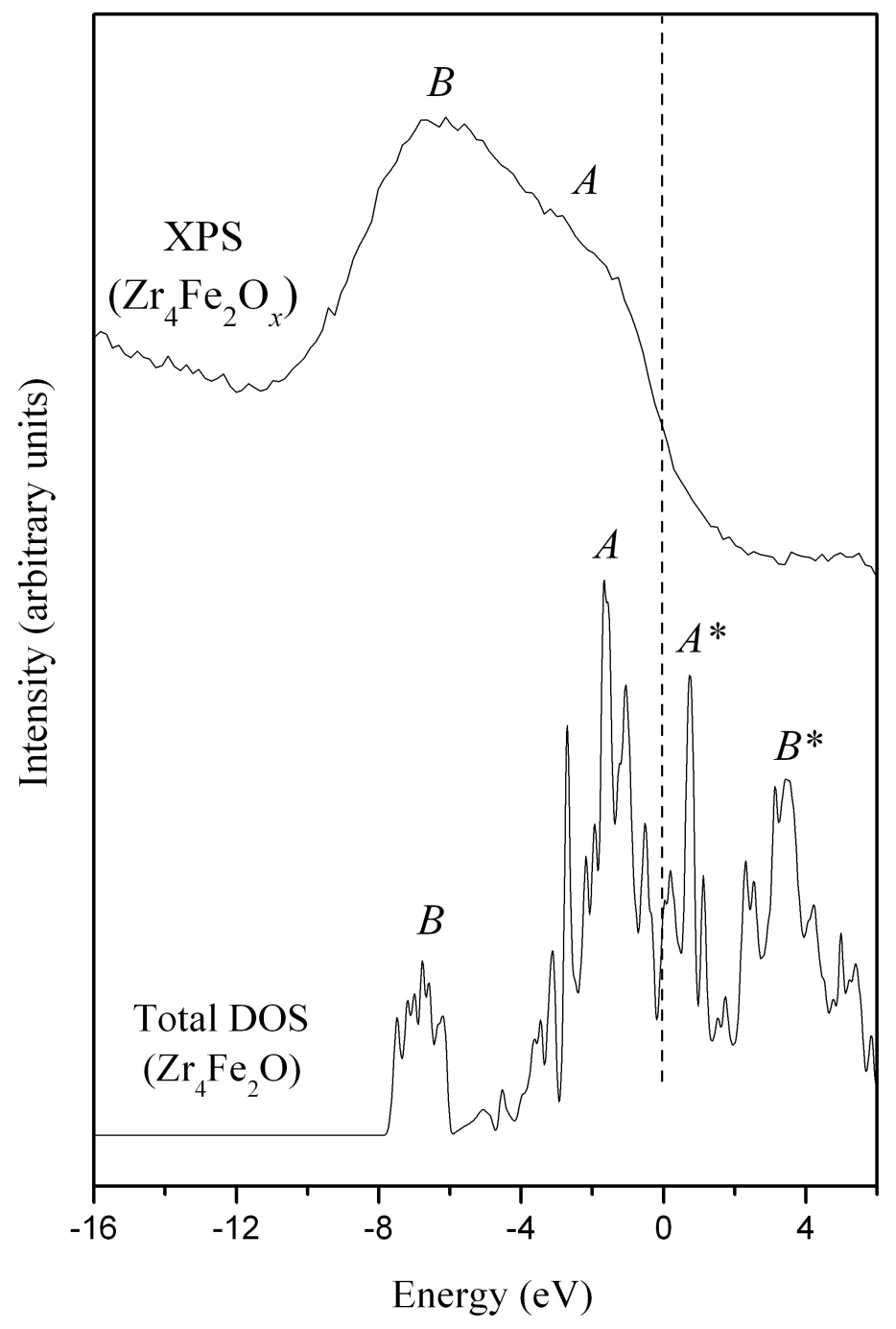

Fig. 6 Comparison on a common energy scale of the XPS valence-band spectrum measured in [13] for $\mathrm{Zr}_{4} \mathrm{Fe}_{2} \mathrm{O}_{0.6}$ and the curve of total DOS of $\mathrm{Zr}_{4} \mathrm{Fe}_{2} \mathrm{O}$ calculated in the present work.

of the valence band is mainly composed from contributions of the $\mathrm{Fe} 3 d$ and $\mathrm{Zr} 4 d$ states. The main contributors at the bottom of the conduction band of $\mathrm{Zr}_{4} \mathrm{Fe}_{2} \mathrm{O}$ are the unoccupied $\mathrm{Fe} 3 d$ and $\mathrm{Zr} 4 d$ states. The results of the APW+LO calculations are confirmed by a comparison on a common energy scale of the curve of total DOS and the XPS valence-band spectrum of the same compound. The electronic structure of $\mathrm{Zr}_{4} \mathrm{Fe}_{2} \mathrm{O}$ resembles that of the other oxygen-stabilized $\eta-\mathrm{Fe}_{3} \mathrm{~W}_{3} \mathrm{C}$-type compounds under study, namely $\mathrm{Zr}_{4} \mathrm{Co}_{2} \mathrm{O}$ and $\mathrm{Zr}_{4} \mathrm{Ni}_{2} \mathrm{O}$. Furthermore, our APW+LO calculations indicate that the electronic structure of the $\mathrm{Zr}_{4} M_{2} \mathrm{O}$ compounds $(M=\mathrm{Fe}, \mathrm{Ni}, \mathrm{Co}$ ) differs from those of binary $\mathrm{Zr}, \mathrm{Fe}, \mathrm{Ni}$, and $\mathrm{Co}$ oxides, in which the $\mathrm{O} 2 p$ states mainly contribute in the upper portion of the valence band with additional significant contributions throughout the whole valence-band region.

\section{References}

[1] A. Chikdene, A. Baudry, P. Boyer, S. Miraglia, D. Fruchart, J.-L. Soubeyroux, Z. Phys. Chem., Neue Folge 163 (1989) 219-224.

[2] F. Bonhomme, K. Yvon, M. Zolliker, J. Alloys Compd. 199 (1993) 129-132.

[3] V.A. Yartys, H. Fjellvåg, B.C. Hauback, A.B. Riabov, J. Alloys Compd. 274 (1998) 217-221.

[4] M.V. Nevitt, J.W. Downey, R.A. Morris, Trans. Metall. Soc. AIME 218 (1960) 1019-1023.

[5] H. Holleck, F. Thümmler, Monatsh. Chem. 98 (1967) 133-134.

[6] R. Mackay, G.J. Miller, H.F. Franzen, J. Alloys Compd. 204 (1994) 109-118.

[7] I.Y. Zavaliy, J. Alloys Compd. 291 (1999) 102-109. 
A.A. Lavrentyev et al., Electronic properties of $\mathrm{Zr}_{4} M_{2} \mathrm{O}(M=\mathrm{Fe}, \mathrm{Co}, \mathrm{Ni})$ intermetallic compounds ...

[8] I.Y. Zavaliy, R. Černy, I.V. Koval'chuk, I.V. Saldan, J. Alloys Compd. 360 (2003) 173-182.

[9] P. Raj, P. Suryanarayana, A. Sathyamoorthy, K. Shashikala, R.M. Iyer, J. Alloys Compd. 178 (1992) 393-401.

[10] A. Nobile, W.C. Mosley, J.S. Holder, K.N. Brooks, J. Alloys Compd. 206 (1994) 83-93.

[11] P. Blaha, K. Schwarz, G.K.H. Madsen, D. Kvasnicka, J. Luitz, WIEN2k, An Augmented Plane Wave + Local Orbitals Program for Calculating Crystal Properties, Technische Universität Wien, Austria, 2001 (ISBN 3-9501031-1-2).

[12] V.V. Atuchin, L.D. Pokrovsky, O.Y. Khyzhun, A.K. Sinelnichenko, C.V. Ramana, J. Appl. Phys. 104 (2008) 133518.

[13] A.A. Lavrentyev, B.V. Gabrelian, P.N. Shkumat, I.Y. Nikiforov, I.Y. Zavaliy, O.Y. Khyzhun, J. Phys. Chem. Solids 74 (2013) 590-594.
[14] M. Morinaga, H. Adachi, M. Tsukada, J. Phys. Chem. Solids 44 (1983) 301-306.

[15] J.P. Perdew, S. Burke, M. Ernzerhof, Phys. Rev. Lett. 77 (1996) 3865-3868.

[16] P.E. Blöchl, O. Jepsen, O.K. Andersen, Phys. Rev. B 49 (1994) 16223-16233.

[17] R.J. Lad, V.E. Henrich, Phys. Rev. B 39 (1989) 13478-13485.

[18] H. Wu, L.-S. Wang, J. Chem. Phys. 107 (1997) 16-21.

[19] Q.-J. Liu, Z.-T. Liu, L.-P. Feng, Physica B 406 (2011) 345-350.

[20] J. Chen, X. Wu, A. Selloni, Phys. Rev. B 83 (2011) 245204.

[21] A.A. Lavrentyev, B.V. Gabrelian, P.N. Shkumat, I.Y. Nikiforov, I.Y. Zavaliy, A.K. Sinelnichenko, A.V. Izvekov, O.Y. Khyzhun, J. Alloys Compd. 492 (2010) 39-43.

[22] O.Y. Khyzhun, V.L. Bekenev, M.V. Karpets, I.Y. Zavaliy, J. Phys. Chem. Solids 73 (2012) 1302-1308. 